\title{
Algumas considerações sobre 1Timóteo 4,1-16 a partir da ética do cuidado de si de Michel Foucault
}

Some considerations about 1Timothy 4,1-16 from the ethics of care of yourself of Michel Foucault

\begin{abstract}
Alfredo dos Santos Oliva
Professor adjunto da Universidade Estadual de Londrina (UEL) no Programa de Pós-Graduação em História, Londrina, PR - Brasil, e-mail: alfredoliva@yahoo.com.br
\end{abstract}

\section{Resumo}

Análise de 1Timóteo 4,1-16 a partir do debate sobre as técnicas de si nos últimos escritos do filósofo francês Michel Foucault (1926-1984). No primeiro subitem, discuto a hipótese de que a obra do autor pode ser analisada a partir de três fases ou eixos temáticos. No segundo, afunilo a análise para a terceira fase do trabalho de Foucault, que pode ser designada de ética do cuidado de si. Por fim, procuro citar exemplos de uso do entorno teórico foucaultiano presente na aproximação de outros "objetos" empíricos, a fim de que fique mais fácil que se compreenda a análise final que faço das orientações dadas pelo autor da Primeira Carta a Timóteo a seu discípulo.

Palavras-chave: História das religiões. Cristianismo antigo. Cânon cristão. Michel Foucault. Cuidado de si. 


\section{Abstract}

Analysis of 1Timothy 4,1-16 from the discussion on the techniques of the self in recent writings of French philosopher Michel Foucault (1926-1984). In the first sub-item discuss the hypothesis that the author's work can be analyzed from three phases or themes. In the second narrows the analysis to the third phase of Foucault's work, which can be called the ethics of self-care. Finally, I try to cite examples of using the surrounding Foucault's theory in this approach to other "objects" empirical, so that it becomes easier to understand the final analysis I make the guidelines given by the author of the First Letter to Timothy his disciple.

Keywords: History of religions. Ancient christianity. Christian Canon. Michel Foucault. Care of self.

\section{Introdução}

Gostaria de fazer um experimento de análise documental diferente (para mim) sobre a temática proposta neste dossiê, que foi a de investigar "ações e relações de poder na literatura bíblica". Escolhi um texto de uma epístola da tradição paulina. Vou analisar o trecho que se encontra em 1 Tm 4,1-16 a partir do debate sobre as técnicas de si nos últimos escritos do filósofo francês Michel Foucault (1926-1984).

A trajetória para levar a termo a minha proposta será composta de um primeiro tópico em que discutirei a hipótese, bastante difundida entre intérpretes do trabalho de Foucault, de que sua obra pode ser analisada a partir de três fases ou eixos temáticos. Pretendo dar algumas informações básicas e globais sobre o trabalho de Foucault e espero que elas venham a orientar o leitor ou leitora no acompanhamento de minhas discussões até o fim deste artigo. Como desejo destacar questões teóricas presentes na terceira fase do trabalho de Foucault, achei interessante começar por uma apresentação das duas fases anteriores de sua obra, ainda que de forma muito breve. No segundo tópico afunilo minha análise em direção à terceira fase do trabalho de Foucault, que pode ser bem designada pela 
expressão "ética do cuidado de si". Nesse momento, construirei um aporte teórico para pensar as relações de poder no primeiro século de nossa era, ocasião em que foi escrita a Primeira Carta a Timóteo, objeto principal deste artigo. O meu problema consiste em analisar se a literatura paulina pode ser caracterizada como pertencente a um conjunto de prescrições que orientavam os cristãos a resistirem a certas formas de poder, presentes no primeiro século, por meio do cultivo do que Foucault chamou de práticas ou técnicas de si.

No terceiro e último tópico, procuro citar exemplos de uso do entorno teórico foucaultiano presente na aproximação de outros "objetos" empíricos, a fim de facilitar a compreensão da análise final que farei das orientações dadas pelo autor da Primeira Carta a Timóteo a seu discípulo. Deter-me-ei no debate e significado de algumas expressões do quarto capítulo da carta para tentar convencer o leitor ou leitora de que o cristianismo é composto de uma série de táticas de resistência e sabotagem de poderes socialmente constituídos e bastante coercitivos. O principal conjunto de estratégias utilizadas poderia globalmente ser designado, nos termos foucaultianos, de técnicas ou cuidado de si.

\section{A hipótese dos três eixos temáticos}

A partir deste ponto gostaria de analisar a hipótese, muito em voga entre intérpretes comtemporâneos do pensamento de Foucault, de que a sua obra seria composta de três eixos temáticos: 1) arqueologia do saber; 2) genealogia do poder; e 3) ética do cuidado de si.

1) A arqueologia do saber compreende pesquisas produzidas entre os anos 1950 e 1960. Os problemas investigados estariam dentro dos limites das duas questões que seguem: que relações mantemos com a verdade por meio do saber científico? Como somos constituídos como sujeitos e objetos da verdade científica? A principal estratégia metodológica do autor giraria em torno do conceito de arqueologia, que poderia ser descrito como um procedimento de escavar verticalmente as camadas descontínuas de discursos com 
a finalidade de trazer à luz práticas e conceitos marginalizados; ou como um esforço para desvelar práticas discursivas que historicamente constituem determinados objetos ou sujeitos.

2) A genealogia do poder engloba pesquisas realizadas ao longo dos anos 1970, quando Foucault passou a lecionar no Collège de France. De forma sintética, poder-se-ia dizer que a questão perseguida pelo filósofo era: que relações mantemos com os outros por meio das estratégias e relações de poder? Suas "precauções de método" gravitariam ao redor do conceito de genealogia, que pode ser descrito como um conjunto de procedimentos para conhecer o passado e desnaturalizar o presente; ou, ainda, como um mapeamento das ascendências do que hoje é pensado, dito e feito, não se tratando de uma interpretação, mas de uma história das muitas interpretações ocultadas ou sedimentadas.

3) A ética do cuidado de si envolve investigações iniciadas no fim dos anos 1970 e que estavam em curso quando Foucault morreu, no ano de 1984. Parece que sua preocupação teórica se voltava para uma resposta à seguinte pergunta: quais são as relações entre verdade, poder e si mesmo? Não havia nesse momento da vida do filósofo uma inovação de caráter metodológico, mas uma continuidade, com procedimentos anteriormente utilizados, que poderia ser muito bem sintetizada pela expressão arqueogenealogia.

É importante ressaltar que essa forma de interpretar globalmente o trabalho de Foucault deve ser realizada com certos cuidados. Claro que estamos diante de uma estratégia de interpretação de sua obra que prima pela dimensão didática. Ninguém vive ou escreve transitando de uma fase para outra, anunciando e transicionando de um momento para outro com intencionalidade totalmente consciente. Esse modo de ver as coisas é possível apenas de forma retrospectiva e com a clareza de que as "fases" não são estanques, nem correspondem à realidade tal qual ela se apresenta, haja visto que a "realidade em si" é algo que não existe. Trata-se, tão somente, de uma forma de ler, interpretar e sintetizar o trabalho complexo de um grande pensador, tornando-o mais digerível ao leitor iniciante. 
Há outra questão que desejo levantar: será que esse modo da obra de Foucault consegue se sustentar a partir do que ele mesmo disse, retrospectivamente, sobre seu trabalho? Tenho lido e ouvido pessoas dizerem que Foucault perseguiu, ao longo das três fases de sua carreira acadêmica, temáticas como o poder ou a constituição das práticas. Quando olhamos para as próprias palavras do estudioso francês somos confrontados pelas seguintes palavras:

eu gostaria de dizer, antes de mais nada, qual foi o objetivo do meu trabalho nos últimos vinte anos. Não foi elaborar o fenômeno do poder nem elaborar os fundamentos de uma tal análise. Meu objetivo, ao contrário, foi criar uma história dos diferentes modos pelos quais, em nossa cultura, os seres humanos tornaram-se sujeitos. Meu trabalho lidou com três modos de objetivação que transformam seres humanos em sujeitos. O primeiro é o modo da investigação, que tenta atingir o estatuto de ciência, como, por exemplo, a objetivação do sujeito do discurso na grammaire générale, na filologia e na lingüística. Ou ainda, a objetivação do sujeito produtivo, do sujeito que trabalha, na análise das riquezas e da economia. Ou, um terceiro exemplo, a objetivação do simples fato de estar vivo na história natural ou na biologia. Na segunda parte do meu trabalho, estudei a objetivação do sujeito naquilo que eu chamarei de "práticas divisoras". O sujeito é dividido no seu interior e em relação aos outros. Esse processo o objetiva. Exemplos: o louco e o são, o doente e o sadio, os criminosos e os "bons meninos". Finalmente, tentei estudar - meu trabalho atual - o modo pelo qual um ser humano torna-se sujeito. Por exemplo, eu escolhi o domínio da sexualidade - como os homens aprenderam a se reconhecer como sujeitos de "sexualidade". Assim, não é o poder, mas o sujeito, que constitui o tema geral das minhas pesquisas (FOUCAULT, 1995, p. 231-232).

Parece que o trecho citado impede uma interpretação que identifique o poder como eixo temático central na obra de Foucault. Ele mesmo, em sucessivas releituras de seu próprio pensamento, colocaria como questão sempre presente em seus escritos a investigação sobre como as subjetividades são constituídas historicamente. Ele não desejava filosofar tomando o sujeito como fundamento, mas sim problematizar a própria vida subjetiva ao torná-la seu "objeto" de investigação. Ao tomar a subjetividade como historicamente constituída, Foucault a transformou em algo relativo; e se é algo relativo, transitório, portanto submetido ao transcurso temporal, 
como qualquer outro "objeto", não pode ser reivindicado como fundamento do conhecimento, como desejava a filosofia moderna desde Descartes.

Mesmo que não permita identificar a temática do poder como questão central de sua obra, há que se ressaltar que a citação acima nos dá uma pista interessante de interpretação do trabalho de Foucault. Se a investigação da constituição das subjetividades foi o seu eixo, esse fato não descarta, evidentemente, a questão do poder. As subjetividades são constituídas por poderes que agem externa e coercitivamente ao sujeito ou por ações que o próprio sujeito empreende sobre si mesmo para se constituir com uma certa (relativa) autonomia em relação ao meio externo.

Ainda há mais lenha a ser colocada na fogueira. Prossigamos. A perspectiva de interpretar o trabalho de Foucault a partir de três momentos parece estar também em sintonia com outro balanço retrospectivo de sua obra, feito quase no fim de sua vida:

os problemas que estudei são os três problemas tradicionais. 1) Que relações mantemos com a verdade através do saber científico, quais são as nossas relações com esses "jogos de verdade" tão importantes na civilização, e nos quais somos simultaneamente sujeitos e objetos? 2) Que relações mantemos com os outros, através dessas estranhas estratégias e relações de poder? Por fim, 3) quais são as relações entre verdade, poder e si mesmo? Gostaria de concluir a entrevista com uma pergunta: o que haveria de mais clássico do que essas questões e de mais sistemático do que passar da questão um à questão dois e à questão três para voltar à questão um? É justamente nesse ponto que me encontro (FOUCAULT, 2004b, p. 300).

O primeiro conjunto de problemas poderia ser descrito como a fase da arquelogia do saber; o segundo, a genealogia do poder; e o terceiro, a ética do cuidado de si. Claro que as coisas não são simples e organizadas dessa forma. Insisto que se trata de uma visão retrospectiva do autor sobre seu próprio trabalho, ou mesmo de estratégias que os leitores contemporâneos buscam para poder enxergar a obra de Foucault de uma maneira um pouco mais didática. Na prática, sabemos que um pensamento não pode ser constituído de fases tão claramente estabelecidas ou decididas. Mas mantenho a hipótese de três fases ou eixos temáticos porque ela tem 
alguma relação com a leitura que o autor fez de seu próprio trabalho e também porque é um poderoso instrumental de compreensão e ensino acerca do trabalho do filósofo francês.

Tendo apresentado, discutido e analisado a hipótese de a obra de Foucault ser estruturada em três fases ou eixos, gostaria de passar para uma análise mais detalhada de suas últimas investigações. Até o presente, em minhas pesquisas, me ocupei muito mais em estudar e compreender o Foucault das duas primeiras fases, mas chegou o tempo em que desejo dedicar mais atenção ao terceiro momento ou eixo temático da obra do filósofo.

\section{Poder e subjetividade em Foucault}

Creio que um excelente ponto de partida para a análise que pretendo empreender sobre a fase final da obra de Foucault seria observar as suas considerações em torno da filosofia do sujeito. Para o referido intelectual, os anos antes e depois da Segunda Guerra Mundial foram dominados pelo que ele denominava de filosofia do sujeito:

para justificar o interesse que atribuo ao que parece ser um assunto extremamente especializado, permitam-me voltar brevemente atrás. Durante os anos que antecederam a Segunda Guerra Mundial, e mais ainda depois da guerra, toda filosofia nos países da Europa continental e na França foi dominada pela filosofia do sujeito. Isto significa que a filosofia se atribuía como tarefa par excellence fundamentar todo o saber e o princípio de qualquer significação no sujeito significante (FOUCAULT, 2004c, p. 93).

O que o autor designa acima como filosofia do sujeito é uma referência clara à produção intelectual, desde os séculos XVI e XVII, que procura fundamentar a construção do conhecimento nas atribuições de significado fornecidas pelo sujeito cognoscente. A vida subjetiva seria a fonte de construção de significados e fundamento metafísico de todo conhecimento.

Foucault faz questão de deixar claro que sua produção intelectual está em evidente distanciamento dessa forma de fazer filosofia. Para ele, no pós-guerra havia duas alternativas teóricas para escapar das armadilhas da filosofia do sujeito: 
com a lucidez demasiadamente fácil do a posteriori [...] eu diria que duas vias podiam conduzir para além dessa filosofia do sujeito. A primeira era a teoria do saber objetivo, entendido como análise dos sistemas de significação, como semiologia. Era a via do positivismo lógico. A segunda era a via aberta por certa escola de linguística, de psicanálise e de antropologia - três disciplinas que se agrupavam sob a rubrica "estruturalismo" (FOUCAULT, 2004c, p. 94).

Foucault insiste que seus escritos não se enquadram em nenhuma das duas formas alternativas existentes no período. Aliás, ele aproveita para reafirmar, mais uma vez, que não era um intelectual estruturalista, "rótulo" que recebeu diversas vezes, mas que jamais aceitou. O fato de não se autoidentificar como estruturalista não deve, todavia, significar que ele não tenha chegado a filosofar de forma convergente com certos preceitos teóricos dessa escola. Gosto demais do trecho citado a seguir porque nele podemos ver o filósofo não apenas afirmando que nunca foi estruturalista, mas até brincando com o fato, destilando sua fina ironia:

não foram estas as vias das quais me servi. Que me permitam declarar, uma vez mais, que não sou estruturalista - eu o confesso com todo o devido pesar -, nem um filósofo analítico. Ninguém é perfeito. Tentei, entretanto, explorar uma outra pista. Tentei sair da filosofia do sujeito fazendo uma genenalogia do sujeito moderno, que abordo como uma realidade histórica e cultural; ou seja, como alguma coisa capaz de se transformar, o que, obviamente, é importante do ponto de vista político (FOUCAULT, 2004c, p. 94).

Como se pode ver, ele não apenas afirma que não era ou foi estruturalista, mas aproveita para dizer também que nunca foi um filósofo analítico. De qualquer maneira, o que importa para nós aqui é que ele se vê como criador ou adepto de um terceiro caminho ou via para sair da filosofia do sujeito. Se não foi estruturalista nem analítico, tem em comum com ambos o fato de ter buscado um percurso teórico para fora da filosofia do sujeito. O caminho perseguido por Foucault foi o de fazer uma genealogia do sujeito - em vez de tomar o sujeito como fundamento do conhecimento, ele o toma como "objeto" de investigação. Ele demonstra que a vida subjetiva está sujeita ao fluxo da história tanto quanto qualquer outro "objeto" que eventualmente viermos a tomar como foco de análise. 
Outro aspecto que merece destaque nesse projeto de saída da filosofia do sujeito é a autocrítica que o autor se faz. Ele procurou fazer uma genealogia do sujeito de formas distintas. Primeiro tentou mostrar como as subjetividades eram constituídas por meio do discurso acadêmico ou científico (arqueologia do saber), depois seguiu a pista das práticas de poder ou classificatórias dos sujeitos (genealogia do poder). Foucault recenheceu a importância dessas estratégias - discurso acadêmico e práticas de poder - na construção das subjetividades, mas acreditava que se deixou levar por estratégias apenas externas e que se colocavam de forma impositivas aos sujeitos. Ele percebeu que havia negligenciado as ações empreendidas pelo próprio sujeito sobre si mesmo no processo de construção ou invenção da sua subjetividade. Vejamos os fatos por meio de suas próprias palavras:

permitam-me fazer aqui, de qualquer forma, a minha autocrítica. Talvez seja possível, se nos ativermos a certas proposições de Habermas, distinguir três tipos principais de técnicas: as técnicas que permitem produzir, transformar, manipular coisas; as técnicas que permitem utilizar sistemas de signos; e, finalmente, as técnicas que permitem determinar a conduta dos indivíduos, impor certas finalidades ou determinados objetivos. Temos, então, as técnicas de produção, as técnicas de significação ou de comunicação, e as técnicas de dominação. Fui me dando conta, pouco a pouco, de que existe, em todas as sociedades, um outro tipo de técnicas: aquelas que permitem aos indivíduos realizar, por eles mesmos, um certo número de operações em seu corpo, em sua alma, em seus pensamentos, em suas condutas, de modo a produzir neles uma transformação, uma modificação, e a atingir um certo estado de perfeição, de felicidade, de pureza, de poder sobrenatural. Chamemos essas técnicas de técnicas de si (FOUCAULT, 2004c, p. 94-95).

Foucault iria dedicar as pesquisas dos seus últimos anos de vida a explorar essa dimensão negligenciada de seu trabalho - as técnicas de si. Tratava-se de investigar as ações empreendidas pelo sujeito sobre si mesmo com vistas a transformar-se em algo distinto do que é. Não são apenas as forças externas (discursos e poderes) que cooptam ou submetem os sujeitos, mas há uma liberdade de autocriação "reservada" às pessoas. O filósofo desejava gastar alguns anos investigando essa nova 
dimensão, fato que se concretizou nos dois últimos volumes de sua História da sexualidade, bem como pelo curso que ministrou no Collège de France nos anos de 1981 e 1982, denominado (ironicamente) de A hermenêutica do sujeito.

O estudioso francês reconhecia que o trabalho de fazer uma genealogia do sujeito no mundo ocidental não deveria apenas se dedicar às disciplinas, como o fizera nos anos 1970, a exemplo do que está publicado em Vigiar e punir. Deveria também debruçar-se sobre as técnicas ou práticas de si, como que produzindo uma visão mais integral e razoável da constituição das subjetividades.

Se quisermos analisar a genealogia do sujeito na civilização ocidental, é preciso considerar não apenas as técnicas de dominação, mas também as técnicas de si. Devemos mostrar a interação que se produz entre os dois tipos de técnicas. Talvez eu tenha insistido demais, quando estudava os hospícios, as prisões etc., nas técnicas de dominação. É verdade que aquilo que chamamos de "disciplina" é algo que tem uma importância real nesse tipo de instituições. Porém ela não passa de um dos aspectos da arte de governar as pessoas em nossas sociedades. Tendo estudado o campo do poder tomando como ponto de partida as técnicas de dominação, gostaria de estudar, durante os próximos anos, as relações de poder partindo das técnicas de si (FOUCAULT, 2004c, p. 95).

O trecho acima permite concluir que Foucault ampliou sua visão do modo como as subjetividades são construídas. Não se trata de um processo unilateral - fatores externos ou internos exclusivamente -, mas da interação entre ambos. Se atentava a um novo universo temático a ser explorado, com isso não estava dizendo que tudo que investigara em décadas anteriores não tivesse sua importância. A nova dimensão - a que investiga as técnicas de si - deveria ser colocada lado a lado com as técnicas disciplinares. Eram dimensões complementares e não contraditórias.

Em outro texto detalha um pouco mais a maneira como funcionavam as técnicas ou práticas de si. Parece que envolviam uma série de atividades que precisavam ser repetidas à exaustão. Englobavam atividades como ascese, abstinência de diversos tipos, memorizações de textos canônicos ou filosóficos, meditações, silêncios, etc.: 
nenhuma técnica, nenhuma habilidade profissional pode ser adquirida sem exercício; não se pode mais aprender a arte de viver, a technê tou biou, sem uma askêsis que deve ser compreendida como um treino de si por si mesmo: este era um dos princípios tradicionais aos quais, muito tempo depois, os pitagóricos, os socráticos, os cínicos deram tanta importância. Parece que, entre todas as formas tomadas por esse treino (e que comportava abstinências, memorizações, exames de consciência, meditações, silêncio e escuta do outro), a escrita - o fato de escrever para si e para outro - tenha desempenhado um papel considerável por muito tempo (FOUCAULT, 2004d, p. 146).

As pesquisas de Foucault em busca desse conjunto de técnicas de si foram empreendidas em direção à antiguidade clássica. Ele passou a investigar essas técnicas entre os antigos gregos e romanos. O filósofo francês se dedicou a um grande conjunto documental que abrangia um extenso recorte temporal, que ia do século V a.C. ao V d.C. Uma definição da expressão cuidado de si nos é apresentada por E. Castro em seu Vocabulário de Foucault:

a expressão "souci de soi" (título do terceiro volume de Histoire de la sexualité) traduz o grego "epiméleia heautoû" (em latim "cura sui"); "cuidado de si mesmo" parece a melhor tradução para o português. $O$ tema do cuidado de si foi consagrado por Sócrates; a filosofia posterior o retomou e, na medida em que ela mesma se concebeu como uma arte da existência, a problemática do cuidado ocupou o centro de suas reflexões. Esse tema acabou ultrapassando os limites da filosofia e alcançou progressivamente as dimensões de uma verdadeira cultura do cuidado de si. Os dois primeiros séculos da época imperial (séculos I-II) podem ser considerados como a idade de ouro da cultura do cuidado de si mesmo (CASTRO, 2009, p. 92-93).

O testemunho dessas pesquisas, encerradas pela morte do autor, está presente no curso que ministrou no Collège de France nos anos de 19811982. A pesquisadora e professora de educação R. Fischer faz uma apresentação bastante entusiasmada do curso mencionado, que foi publicado sob a forma de livro e traduzido para o português. Vejamos sua avaliação da obra:

a meu ver, um dos livros mais fascinantes publicados no início deste século, na área da filosofia, é A hermenêutica do sujeito, de Michel Foucault [...], no qual estão transcritas as aulas do curso que o filósofo proferiu no 
Collège de France em 1982. Essa obra - sem temer redundâncias - efetivamente opera algo especial em nós, naqueles que a leem e a estudam. Nela encontramos um Foucault que, sem deixar de estar ocupado com a leitura crítica e política dos dispositivos de poder que tanto o marcaram em sua trajetória acadêmica e existencial, concentra-se nas questões éticas e estéticas da produção de si mesmo. Ele busca, nos filósofos da Antiguidade clássica grega e romana, fonte para pensar não mais prioritariamente o problema das diferentes formas de sujeição, mas antes o tema dos modos de subjetivação. Estes, na leitura de Foucault, apontavam para práticas de si mesmo e práticas da verdade nas quais estariam mais evidentes formas de liberdade do sujeito do que exatamente processos de aprisionamento. Trata-se de uma dimensão nova em sua obra: deixar que o político seja também impregnado por indagações éticas e, nesse caminho, pensar na possibilidade de um trabalho sobre si mesmo para além de assujeitamentos, na direção de uma estética da existência (FISCHER, 2009, p. 93-94).

A hermenêutica do sujeito é tratada como um dos livros mais fascinantes dentre os que foram publicados no início deste século no campo da filosofia. Li o artigo da professora antes de ter acesso ao curso do filósofo francês e pensei, inicialmente, que se tratava de exagero, coisa de admiradores apaixonados do pensamento de Foucault. Tão logo comecei a ler o referido curso, passei a partilhar da opinião de Fischer. Mais que isso: à medida que ia correndo os olhos sobre as páginas do curso ministrado no Collège de France, me lembrava de alguns trechos do cânon cristão que sabia quase de cor. Percebi que algumas expressões que o filósofo investigava entre os antigos gregos e romanos, e que serviam para caracterizar as técnicas de si, estavam também em alguns textos do cristianismo primitivo. Algumas dessas descobertas é o que desejo partilhar com a leitora ou leitor no próximo tópico.

\section{Algumas considerações sobre 1Tm 4,1-16}

Antes de começar a análise do texto bíblico em destaque, gostaria de mencionar brevemente dois exemplos de apropriação e uso do debate de Foucault sobre a ética do cuidado de si em campos diferentes dos que serviram de base para o mencionado autor. 
O primeiro exemplo é proveniente de uma análise da arte zen. O treinamento à exaustão e a repetição até atingir a perfeição foram vistos por T. Hara como um equivalente japonês de práticas comuns entre os antigos gregos.

É possível reconhecer um paralelo entre as práticas de si valorizadas pelos filósofos gregos e os treinos praticados pelos japoneses que almejavam a perícia na arte de conduzir suas vidas. [...] Essa assimilação "fisiológica" de um discurso ou técnica é fundamental para o entendimento das artes japonesas, seja no campo da guerra ou criação estética. Encarnar uma técnica, uma postura, uma verdade (entre os japoneses isso é realizado, basicamente, através de uma exaustiva repetição de um mesmo movimento) compõe processo de desprendimento de si (HARA, 2010, p. 223).

O segundo exemplo vem do campo da educação. O cinema e a televisão podem ser considerados como instrumentos de criação e transformação de si fundamentais na ação educacional contemporânea. Creio que isso vale tanto para educadores como para educandos. Assistir a um filme pode ser mais do que um mero entretenimento. Pode vir a ser a observação de trajetórias de personagens que se reinventam no enredo e que, por isso mesmo, podem operar como estímulos ou exemplos do que podemos fazer de nossas vidas.

Proponho-me a discutir aqui o tema da formação ético-estética docente tendo como ferramenta teórica principal Michel Foucault e sua hermenêutica do sujeito, utilizando, digamos, como material empírico, algumas narrativas audiovisuais do cinema e da televisão. Suponho que poderia fazer parte importante da formação docente a educação do olhar, a educação de sensibilidade, a educação ética, cuja fonte poderia ser, dentre tantos possíveis, alguns exercícios de imersão nas linguagens audiovisuais: exercícios de entrega aos sons, movimentos, diálogos e cores das imagens do cinema e da televisão; exercícios de entrega a narrativas que fogem aos esquemas convencionais das chamadas estruturas de consolação. Tais exercícios, a meu ver, poderiam comparar-se, com todas as salvaguardas necessárias, a uma espécie de práticas consigo mesmo, catapultadas pelo acesso a produções fílmicas ou televisivas que escapam aos padrões convencionais e que sugerem ao espectador uma elaboração ética de si mesmo absolutamente necessária em nossos tempos. Tempos de impunidade 
desmesurada, tempos de exposição de si mediada por sofisticadas tecnologias digitais, em meio a um excesso de imagens e de informação; tempos de quase-anulação de referências éticas para gerações mais jovens; tempos de imensa dificuldade de discernimento e hierarquia entre textos e imagens que se confundem diante de nossos olhos, reduzidos muitas vezes a uma plana mesmice - seja pelo excesso de imaginário produzido, seja pela falta de instrumental para minimamente operar seleções com algum critério (FISCHER, 2009, p. 94-95).

Creio que os dois exemplos acima me deixam numa posição mais confortável para afirmar que não seria nada absurdo pensar em práticas de si em campos distintos do mundo clássico ou greco-romano, principalmente se for considerado que a Primeira Carta a Timóteo é um documento do primeiro século e foi escrito em língua grega durante uma fase de expansão da cultura helenística. No mesmo verbete, cuidado de si, anteriormente citado, E. Castro, em seu trabalho magistral de sistematizar os conceitos mais importantes do trabalho de Foucault, elaborou uma síntese histórica interessante para as minhas observações:

essa história iria desde as primeiras formas filosóficas do cuidado de si, no século $\mathrm{V}$ a.C., até o ascetismo cristão, século $\mathrm{V}$ d.C. Uma história, então, de mil anos na qual haveria que distinguir, pelo menos, três momentos fundamentais: o momento socrático (século $\mathrm{V}$ a.C.), a idade de ouro da cultura do cuidado de si (séculos I-II) e a passagem do ascetismo pagão ao ascetismo cristão (séculos IV-V) (CASTRO, 2009, p. 93).

Como se pode notar, a Primeira Carta a Timóteo foi escrita durante o período a que Foucault denomina "idade de ouro" da cultura do cuidado de si. O que me parece muito instigante é o fato de o filósofo francês empreender um conjunto de estudos tão extenso sobre um corpus documental greco-romano e não explorar detalhadamente documentos do cânon cristão que foram contemporâneos e poderiam ser classicados como pertencentes à época áurea da cultura do cuidado de si. Como se poderá notar no texto bíblico, até expressões destacadas por Foucault como características das técnicas de si aparecem em 1Tm 4,1-16.

É discutível entre os estudiosos do Novo Testamento se a carta é de autoria do apóstolo Paulo, como a tradição o tem considerado, ou se 
se trata de trabalho de um de seus discípulos. O fato é que a antiguidade não seguia os mesmos e rígidos padrões de estabelecimento de autoria das pessoas dos dias de hoje. Usar o nome de uma outra pessoa em um texto poderia indicar uma forma de se identificar como admirador do seu pensamento ou mesmo um modo de homenageá-la. Não creio ser necessário discutir esta questão com mais profundidade no momento. Basta que consideremos que a carta faz parte da tradição paulina, o que pode significar que ele ou um de seus discípulos ou admiradores é o seu autor.

No meu modo de ver, o que merece destaque é que uma pessoa experimentada na fé cristã está escrevendo uma carta para uma outra um pouco menos versada, mas que também ocupa uma posição de direção espiritual no seio de uma comunidade cristã pioneira. $\mathrm{O}$ tom do texto é o de um mestre espiritual que exorta seu seguidor a se comportar de uma certa maneira em detrimento de outras. Vejamos, sem mais demora, o trecho para que, a posteriori, possamos comentá-lo e analisá-lo.

Ora, o Espírito afirma expressamente que, nos últimos tempos, alguns apostatarão da fé, por obedecerem a espíritos enganadores e a ensinos de demônios, pela hipocrisia dos que falam mentiras e que têm cauterizada a própria consciência, que proíbem o casamento e exigem abstinência de alimentos que Deus criou para serem recebidos, com ações de graças, pelos fiéis e por quantos conhecem plenamente a verdade; pois tudo que Deus criou é bom, e, recebido com ações de graças, nada é recusável, porque, pela palavra de Deus e pela oração, é santificado. Expondo estas coisas aos irmãos, serás bom ministro de Cristo Jesus, alimentado com as palavras da fé e da boa doutrina que tens seguido. Mas rejeita as fábulas profanas e de velhas caducas. Exercita-te, pessoalmente, na piedade. Pois o exercício físico para pouco é proveitoso, mas a piedade para tudo é proveitosa, porque tem a promessa da vida que agora é e da que há de ser. Fiel é esta palavra e digna de inteira aceitação. Ora, é para esse fim que labutamos e nos esforçamos sobremodo, porquanto temos posto a nossa esperança no Deus vivo Salvador de todos os homens, especialmente dos fiéis. Ordena e ensina estas coisas. Ninguém despreze a tua mocidade; pelo contrário, torna-te padrão dos fiéis, na palavra, no procedimento, no amor, na fé, na pureza. Até à minha chegada, aplica-te à leitura, à exortação, ao ensino. Não te faças negligente para com o dom que há em ti, o qual te foi concedido mediante profecia, com a imposição das mãos do presbitério. Medita estas coisas e nelas sê diligente, para que o teu progresso a todos seja manifesto. Tem cuidado de ti mesmo 
e da doutrina. Continua nestes deveres; porque, fazendo assim, salvarás tanto a ti mesmo como aos teus ouvintes (1Tm 4,1-16, ARA).

Eu sintetizaria o conteúdo do texto de uma forma didática. Já disse que um mestre espiritual escreve para um discípulo para orientá-lo no seu progresso pessoal e ministerial. Agora basta destacar as ações descritas no texto:

1) ele começa suas considerações pela constatação de que nos últimos tempos as pessoas passariam a aderir a ensinamentos de diversos tipos, ensinamentos esses estranhos ao cristianismo, e o papel do discípulo seria o de cuidar de si e do rebanho que guiava para que não se deixassem seduzir por tais doutrinas;

2) várias ações poderiam servir como antídoto para a vida pessoal e ministerial contra os ensinos estranhos: reconhecer e ensinar aos demais a respeito do erro alheio, exercitar-se na piedade, meditar sobre os ensinamentos corretos, zelar pelo dom que habitava no seu interior, cuidar de si e da doutrina, permanecer nos deveres prescritos, etc.;

3) a finalidade do seguimento de todas as orientações fornecidas é a salvação, de si e dos demais.

Creio que nossa análise se completaria com o detalhamento de algumas expressões que aparecem no texto bíblico original a partir desses três aspectos destacados.

(1) Nos últimos tempos as pessoas passariam a aderir a ensinamentos estranhos ao cristianismo de diversos tipos e o papel do discípulo seria o de cuidar de si e do rebanho que estava guiando para que não se deixassem seduzir por eles. A palavra ensino ( $\delta\llcorner\delta \alpha \sigma \kappa \alpha \lambda \iota)$ aparece na parte

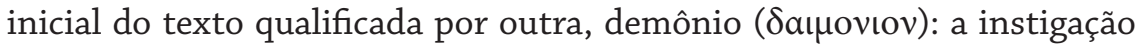
ao erro doutrinário se deve a ensinamentos demoníacos. O primeiro termo grego pode ser compreendido como "ensino, instrução; aquilo que é ensinado, doutrina; ensinamentos, preceitos" (STRONG, 2006). A segunda palavra pode ser descrita como um "poder divino, deidade, divindade; espírito, ser inferior a Deus, superior ao homem; espíritos maus ou os mensageiros e ministros do mal" (STRONG, 2006). Uma série de ações 
qualificadas de forma negativa são desencadeadas por ação demoníaca: hipocrisia, proliferação da mentira, cauterização da consciência dos fiéis, proibição de casamentos, abstinência de alimentos, etc.

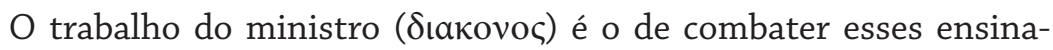
mentos desvirtuados, portanto demoníacos. Ministro pode ser designado como "alguém que executa os pedidos de outro, especialmente de um mestre, servo, atendente, ministro; o servo de um rei; diácono, alguém que, em virtude do ofício designado a ele pela igreja, cuida dos pobres e tem o dever de distribuir o dinheiro coletado para uso deles; garçom, alguém que serve comida e bebida" (STRONG, 2006). Timóteo é instado a agir como bom ministro de Deus e que guerreia contra ensinos estranhos que estavam penetrando sorrateiramente no interior de uma comunidade cristã primitiva. Uma questão dos dias de hoje que para nós seria apenas de caráter doutrinário ou intelectual, para o mestre cristão assume dimensões de uma luta do bem contra o mal, uma verdadeira "batalha espiritual", cujo escopo era a salvação ou a perdição das almas.

(2) Várias ações poderiam servir como antídoto, para a vida pessoal e ministerial, contra os ensinos estranhos: reconhecer e ensinar aos demais a respeito do erro alheio, exercitar-se na piedade, meditar sobre os ensinamentos corretos, zelar pelo dom que habitava no seu interior, cuidar de si e da doutrina, permanecer nos deveres prescritos. Penso que aqui está o coração do texto, assim como o centro do meu interesse analítico. A orientação do mestre é que o discípulo deve exercitar ( $\gamma \cup \mu v a \zeta \omega)$ a si mesmo ( $\sigma \varepsilon \alpha v \tau o v)$ na piedade $(\varepsilon v \sigma \varepsilon \beta \varepsilon\llcorner\alpha)$. O verbo pode ser traduzido por "exercitar nu (numa 'palaestra' ou escola de atletas); exercitar vigorosamente, por qualquer meio, o corpo ou a mente" (STRONG, 2006); e, em piedade, o objetivo do exercício seria a "reverência, respeito; fidelidade a Deus, religiosidade” (STRONG, 2006). Poderia tratar-se de um exercício físico ou mental, realizado em proporções exaustivas, na vida religiosa; só assim o discípulo estaria preparado para enfrentar a batalha doutrinária contra o mundo das trevas. O exercício físico chega a ser colocado em segundo plano, diante da importância da destreza na vida piedosa.

O destinatário das exortações é instruído a transmitir a mensagem e o ensino cristão a outras pessoas. Ele também não deve deixar que os seus discípulos desprezem a sua pouca idade. Mesmo sendo novo, deve se 


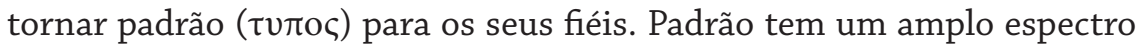
de significado, podendo ser descrito como

forma, ensino que expressa a essência e a substância da religião e que a representa para a mente; exemplo, no sentido técnico, modelo de acordo com o qual algo deve ser feito, num sentido ético, exemplo dissuasivo, padrão de advertência de eventos destrutivos que servem como admoestação ou advertência a outros, exemplo a ser imitado de homens que merecem imitação, num sentido doutrinal de um tipo, i.e., uma pessoa ou coisa que prefigura algo ou alguém (messiânico) futuro (STRONG, 2006).

Os exercícios espirituais deveriam ser tão intensos que passariam a marcar a vida de Timóteo de uma tal forma que ele seria como que um farol para as suas ovelhas, de modo a refletir, por meio de seu comportamento exterior, as marcas da piedade cristã. Sua vida deveria espelhar externamente a palavra ( $\lambda$ oүo $)$, de significado complexo:

do ato de falar palavra, proferida a viva voz, que expressa uma concepção ou idéia, o que alguém disse palavra, os ditos de Deus, decreto, mandato ou ordem, dos preceitos morais dados por Deus, profecia do Antigo Testamento dado pelos profetas, o que é declarado, pensamento, declaração, aforismo, dito significativo, sentença, máxima, discurso, o ato de falar, fala, a faculdade da fala, habilidade e prática na fala, tipo ou estilo de fala, discurso oral contínuo, instrução, doutrina, ensino, algo relatado pela fala; narração, narrativa, assunto em discussão, aquilo do qual se fala, questão, assunto em disputa, caso, processo jurídico, algo a respeito do qual se fala; evento, obra; seu uso com respeito à MENTE em si, razão, a faculdade mental do pensamento, meditação, raciocínio (STRONG, 2006).

Ele deveria ser também padrão no seu procedimento ( $\alpha$ $\alpha \sigma \tau \rho \circ \varphi \eta)$ ou "modo de vida, conduta, comportamento, postura" (STRONG, 2006). Seu modo ou estilo de vida necessitaria ser tão intensamente submerso nos valores do cristianismo que as suas ovelhas deveriam olhar para ele e ver um exemplo de como elas próprias deveriam viver também.

O mesmo pode ser dito em relação ao amor ( $a \gamma a \pi \eta$ ), palavra fundamental para a identidade cristã primitiva, que significa "amor fraterno, de irmão, afeição, boa vontade, amor, benevolência; banquetes de amor" (STRONG, 2006). 
A sua fé ( $\pi \imath \sigma \tau \iota \varsigma)$ também deveria ser padrão para os fiéis. Fé pode significar muitas coisas, como se pode verificar a seguir:

convicção da verdade de algo, fé; no NT, de uma convicção ou crença que diz respeito ao relacionamento do homem com Deus e com as coisas divinas, geralmente com a idéia inclusa de confiança e fervor santo nascido da fé e unido com ela, relativo a Deus, a convicção de que Deus existe e é o criador e governador de todas as coisas, o provedor e doador da salvação eterna em Cristo, relativo a Cristo, convicção ou fé forte e benvinda de que Jesus é o Messias, através do qual nós obtemos a salvação eterna no reino de Deus, a fé religiosa dos cristãos, fé com a idéia predominante de confiança (ou confidência) seja em Deus ou em Cristo, surgindo da fé no mesmo; fidelidade, lealdade, o caráter de alguém em quem se pode confiar (STRONG, 2006).

Também a sua pureza (aүveı a) precisaria ser exemplar. Essa palavra poderia referir-se à "castidade, inocência, pureza de vida" (STRONG, 2006). A conduta sexual ou o seu modo inocente de encarar a vida deveriam ser exemplares para os seus seguidores.

Uma fonte de exercícios espirituais tipicamente judaico-cristã é a ação de meditar ( $\mu \varepsilon \lambda \varepsilon \tau \alpha \omega)$, ou "cuidar de, aplicar-se cuidadosamente a, praticar; meditar, i.e., imaginar, inventar, usado pelos gregos a respeito da ponderação meditativa e da prática de oradores e retóricos" (STRONG, 2006). A meditação deveria ser tão cuidadosa e intensa que o seu progres-

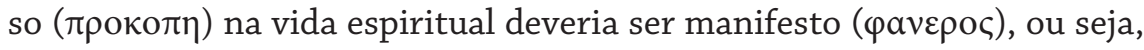
"aparente, manifesto, evidente, reconhecido; claramente reconhecido ou identificado" (STRONG, 2006).

As expressões presentes nas últimas palavras do texto nos colocam diretamente no interior do campo semântico do universo vocabular explorado por Michel Foucault. O autor da epístola exorta a Timóteo: "tem

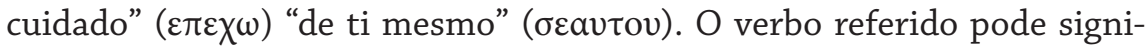
ficar "ter ou segurar firmemente sobre, aplicar, observar, atender a, dar atenção a; exibir, apresentar; conferir cuidadosamente, adiar, parar, suspender" (STRONG, 2006). E ainda lhe é recomendado continuar ( $\varepsilon \pi \mu \varepsilon v \omega)$ nos deveres, ou seja, "permanecer em ou com, esperar, demorar, continuar, permanecer, de esperar em um lugar, perseverar, continuar, de algo que 
continua, no trabalho de ensinar, da bênção que alguém espera receber, que denota a ação na qual se persiste" (STRONG, 2006).

(3) A finalidade do seguimento de todas as orientações fornecidas é salvação, de si e dos demais. Por que persistir em exercícios tão rigorosos sobre si, de modo a transformar-se em algo distinto que pode servir de inspiração para que outros vejam e também se transformem em algo distinto? A resposta está no verbo salvar $(\sigma \omega \zeta \omega)$, o que deve ocorrer consigo mesmo e com os seus respectivos ouvintes. Também o campo de significado do verbo salvar é amplo:

salvar, manter são e salvo, resgatar do perigo ou destruição, alguém (de dano ou perigo), poupar alguém de sofrer (de perecer), i.e., alguém sofrendo de uma enfermidade, fazer bem, curar, restaurar a saúde, preservar alguém que está em perigo de destruição, salvar ou resgatar, salvar no sentido técnico usado na Bíblia, negativamente, livrar das penalidades do julgamento messiânico, livrar dos males que dificultam a recepção do livramento messiânico (STRONG, 2006).

Acredito que o detalhamento das expressões originais presentes no texto bíblico foi importante para nos convencer de que há uma sintonia entre a Primeira Carta a Timóteo e os textos que foram objeto de investigação pelo filósofo francês em seu projeto de realizar uma "hermenêutica do sujeito". Penso que, se minhas interpretações forem razoáveis, uma nova senda na pesquisa acadêmica poderia ser aberta. As práticas religiosas são particularmente ricas em diversas experiências culturais de "cuidados de si". O estudo da história das religiões poderia ser explorado sob uma óptica foucaultiana, especialmente a partir dos trabalhos de sua terceira fase. Mais experimentos teóricos deste tipo precisariam ser realizados com textos bíblicos e com religiões de outras épocas e tradições para que possamos vislumbrar a fecundidade teórica dos últimos escritos de Michel Foucault.

\section{Referências}

CASTRO, E. Vocabulário de Foucault: um percurso pelos seus temas, conceitos e autores. Belo Horizonte: Autêntica, 2009. 
FISCHER, R. M. B. Docência, cinema e televisão: questões sobre a formação ética e estética. Revista Brasileira de Educação, Rio de Janeiro, v. 14, n. 40, 2009. Disponível em: 〈http://www.scielo.br/pdf/rbedu/v14n40/v14n40a08.pdf >. Acesso em: 7 ago. 2010.

FOUCAULT, M. O sujeito e o poder. In: RABINOW, P.; DREYFUS, H. Michel Foucault, uma trajetória filosófica: para além do estruturalismo e da hermenêutica. Rio de Janeiro: Forense Universitária, 1995. p. 231-249.

FOUCAULT, M. A hermenêutica do sujeito: curso dado no Collège de France (1981-1982). São Paulo: Martins Fontes, 2004a.

FOUCAULT, M. Verdade, poder e si mesmo. In: MOTTA, M. B. (Org.). Michel Foucault: ética, sexualidade, política. Rio de Janeiro: Forense Universitária, 2004b. p. 294-300. (Ditos e Escritos V).

FOUCAULT, M. Sexualidade e solidão. In: MOTTA, M. B. (Org.). Michel Foucault: ética, sexualidade, política. Rio de Janeiro: Forense Universitária, 2004c. p. 92103. (Ditos e Escritos V).

FOUCAULT, M. A escrita de si. In: MOTTA, M. B. (Org.). Michel Foucault: ética, sexualidade, política. Rio de Janeiro: Forense Universitária, 2004d. p. 144-162. (Ditos e Escritos V).

HARA, T. Liberdade da ação: as artes zen e as práticas de si. In: RAGO, M. (Org.). Foucault e as estéticas da existência. Revista Aulas, Campinas, n. 7, 2010. Disponível em: <http://www.unicamp.br/ aulas/07.htm>. Acesso em: 7 ago. 2010.

STRONG, J. Léxico hebraico, aramaico e grego de Strong. In: Biblioteca digital da Bíblia. Barueri: SBB, 2006. 1 CD-ROM.

Recebido: 13/06/2010

Received: 06/13/2010

Aprovado: 22/07/2010

Approved: 07/22/2010 